\title{
Note from the editors: A new virus bringing back memories from the past
}

Eurosurveillance editorial team (eurosurveillance@ecdc.europa.eu) ${ }^{1}$

1. European Centre for Disease Prevention and Control (ECDC), Stockholm, Sweden

Citation style for this article:

Eurosurveillance editorial team. Note from the editors: A new virus bringing back memories from the past. Euro Surveill. 2012;17(39):pii=20284. Available online: http://www.eurosurveillance.org/ViewArticle.aspx?Articleld=20284

In recent days, public health experts and healthcare workers around the world are alert following the discovery of a new human coronavirus causing severe respiratory illness. Two cases, both with connection to Saudi Arabia, were communicated through ProMED on 20 and 23 September respectively $[1,2]$.

Many health professionals still have vivid memories of the alert that followed the death of an American businessman in a hospital in Hanoi, Vietnam, in early 2003 after having travelled to China, and the following outbreak of severe acute respiratory syndrome (SARS). This triggered worldwide alarm and containment measures. During the outbreak, there was excellent collaboration between global players and institutions, on various levels (i.e. public health institutions, laboratories and hospitals) and new ways of communicating proved to be highly value for the exchange of information. The last case of SARS occurred in China in May 2004: thereafter the virus seemed to have disappeared and has not resurfaced since.

The public health world is currently looking closely into the two recent cases of coronovirus infection. Similar to SARS, the two patients had/have symptoms of severe respiratory illness and the virus comes from the same family, Coronaviridae. However, there are some marked differences. The virus is not the same: laboratory analyses have proven that the new virus is not a
SARS-like virus. Furthermore, the two confirmed cases occurred with a gap of three months between them and there is no evidence of a direct epidemiological link.

Much remains unknown at the moment and information that would allow us to make a final judgment about the disease is missing. Two rapid communications in this issue give a timely account of the recommended public health measures and assays to detect the virus. On the basis of the limited evidence currently available, the risk for person-to-person transmission, as assessed by the European Centre for Disease Prevention and Control (ECDC) in a rapid risk assessment, is considered low [3]. Eurosurveillance will continue to provide more information as it becomes available.

\section{References}

1. ProMED-mail. Novel coronavirus - Saudi Arabia: human isolate. Archive Number: 20120920.1302733. 20 Sep 2012. Available from: http://www.promedmail.org/ $p=2400: 1000$

2. ProMED-mail. Novel coronavirus - Saudi Arabia (03): UK HPA, WHO, Qatar. Archive Number: 20120923.1305982. 23 Sept 2012. Available from: http://www.promedmail. org/? $p=2400: 1000$

3. European Centre for Disease Prevention and Control (ECDC). Severe respiratory disease associated with a novel coronavirus, 24 September 2012. Rapid risk assessment. Stockholm: ECDC; 2012. Available from: http://www. ecdc.europa.eu/en/publications/Publications/RRA-Novelcoronavirus-final20120924.pdf Lorem ipsum dolor sit amet, consectetur adipiscing elit. Etiam in ligula vel lectus blandit euismod ut vel enim. Duis eget fringilla eros. Mauris laoreet felis non massa placerat tincidunt. Suspendisse neque arcu, malesuada dignissim condimentum et, gravida et lectus. 